\title{
Review \\ Adaptive Servo-Ventilation as a Novel Therapeutic Strategy for Chronic Heart Failure
}

\author{
Teruhiko Imamura ${ }^{1, *(\mathbb{D},}$ Nikhil Narang ${ }^{2}$ and Koichiro Kinugawa ${ }^{1}$ \\ 1 Second Department of Internal Medicine, University of Toyama, 2630 Sugitani, Toyama 930-0194, Japan; \\ kinugawa-tky@umin.ac.jp \\ 2 Advocate Christ Medical Center, Oak Lawn, IL 60453, USA; nikhil.narang@gmail.com \\ * Correspondence: teimamu@med.u-toyama.ac.jp; Tel.: +81-76-434-2281; Fax: +81-76-434-5026
}

Citation: Imamura, T.; Narang, N.; Kinugawa, K. Adaptive

Servo-Ventilation as a Novel

Therapeutic Strategy for Chronic

Heart Failure. J. Clin. Med. 2022, 11,

539. https://doi.org/10.3390/

jcm11030539

Academic Editors: Michał Ciurzyński and Justyna Domienik-Karłowicz

Received: 6 December 2021

Accepted: 20 January 2022

Published: 21 January 2022

Publisher's Note: MDPI stays neutral with regard to jurisdictional claims in published maps and institutional affiliations.

Copyright: (C) 2022 by the authors. Licensee MDPI, Basel, Switzerland. This article is an open access article distributed under the terms and conditions of the Creative Commons Attribution (CC BY) license (https:// creativecommons.org/licenses/by/ $4.0 /$ )

\begin{abstract}
The introduction of new therapeutics for patients with chronic heart failure, including sacubitril/valsartan, sodium-glucose cotransporter 2 inhibitors, and ivabradine, in addition to betablockers, angiotensin converting enzyme inhibitors, and mineralocorticoid receptor antagonists, lends an opportunity for significant clinical risk reduction compared to what was available just one decade ago. Further clinical options are needed, however, for patients with residual clinical congestion refractory to these therapies. Adaptive servo-ventilation is a novel therapeutic option to address significant clinical volume in cases resistant to medical therapy. The aggregate benefit of these additional therapeutic strategies in addition to foundational medical therapy may be a promising option in the selected candidates who do not achieve acceptable clinical and quality-of-life improvements with oral medical therapy alone. Now is the era to reconsider the implication of an adaptive servo-ventilation-therapy-incorporated medical therapeutic strategy for patients with congestive heart failure.
\end{abstract}

Keywords: heart failure; hemodynamics; congestion

\section{Introduction}

Several novel therapies have been introduced over the last decade that both improve quality of life and reduce mortality in patients with chronic heart failure, including sacubitril/valsartan (ARNI), sodium-glucose cotransporter 2 (SGLT2) inhibitor, and ivabradine [1]. Up-titration of neurohormonal agents including beta-blockers and mineralocorticoid receptor antagonists to maximal doses in addition to these new therapies is essential to achieve the best clinical benefit [2]. The additional risk reduction for heart failure hospitalization or death with contemporary four-tier guideline-directed medical therapy (ARNI, beta-blocker, mineralocorticoid inhibitor, and SGLT2i) compared to angiotensin-converting enzyme inhibitors and beta-blockers alone is $>50 \%$. The guidelines of the Japanese Circulation Society recently published a focused update to emphasize the importance of these life-saving therapies, with a clear recommendation of urgency to rapidly up-titrate these therapies to doses specified in respective landmark clinical trials [3].

In addition to the survival benefit, improvement in patient-reported outcomes including functional status and quality of life is also of paramount importance [4]. Much of this is related to the treatment of congestion. Although these new medical therapies significantly reduce the burden of congestions, some patients suffer from residual volume overload that considerably reduces functional capacity. Furthermore, adequate decongestion at index discharge following heart failure hospitalization is unsurprisingly strongly associated with clinical outcomes [5]. Loop diuretics are conventional tools to treat pulmonary and systemic congestion [6]. Tolvaptan, vasopressin type-2 receptor antagonist, is a potent natriuretic agent that has been utilized for a decade [7]. Tolvaptan as a diuretic therapy improves pulmonary/systemic congestion while not worsening renal function [8]. The cost of this medication in addition to lack of evidence when combined with contemporary heart 
failure therapies are limiting factors to justify the widespread implementation of tolvaptan. There remains a gap in care for patients with residual congestion, for which nonmedical therapeutic strategies should be considered.

Adaptive servo-ventilation (ASV; AutoSet-CS; ResMed, Sydney, Australia) is a noninvasive, positive pressure ventilation tool that reduces work of breathing, suppresses sympathetic nervous system activation, and improves pulmonary/systemic congestion via decreasing cardiac preload and afterload in patients with congestive heart failure, if appropriately utilized at least for $4 \mathrm{~h}$ during the night (Figure 1) [9]. Importantly, this occurs irrespective of the existence of sleep-disordered breathing [10]. Although large-scale randomized control trials of ASV in patients with chronic heart failure did not demonstrate a mortality benefit [11], ASV is still being utilized with success in some scenarios to improve patient symptomology [12].

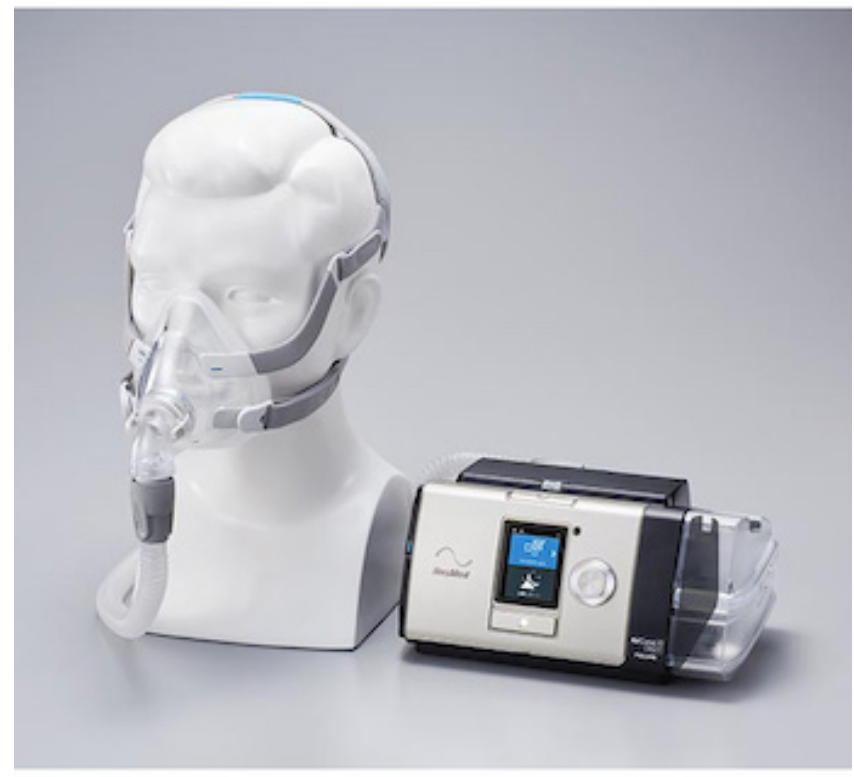

Figure 1. Adaptive servo-ventilation device set.

We believe that ASV therapy can be an effective strategy in managing persistent pulmonary/systemic congestion refractory to medical treatment [13], and should be reconsidered as part of the therapeutic armamentarium in patients with chronic heart failure, even in the era when novel medical agents have been introduced, if appropriately utilized as discussed in this review.

\section{Management of Congestion in the Current Era}

Adequate control of congestion is a critically important goal in chronic heart failure management to both reduce mortality and morbidity and improve patients' symptomology and quality of life [14]. Furthermore, residual pulmonary congestion misdiagnosed by clinical assessment at index discharge is associated with worse clinical outcomes [5].

Sacubitril/valsartan was the first of the new medical therapies in patients with chronic heart failure shown to reduce mortality and morbidity compared to the enalapril arm in the PARADIGM-HF trial [15]. However, the secondary analysis demonstrated reduced efficacy of sacubitril/valsartan in patients with multiple signs of congestion based on clinical exam [16]. SGLT2 inhibitors have pleiotropic benefits with no single direct mechanism to explain the substantial clinical benefit in patients with heart failure and reduced ejection fraction. Furthermore, there is a longitudinal benefit in patients with chronic kidney disease with and without heart failure, which is unique among the current heart failure-specific therapies [17]. However, the renoprotective effect of SGLT2 inhibitors was less expected in patients with insufficient cardiac unloading, indicated as higher plasma B-type natriuretic peptide levels [18]. The additive effects of these novel medical therapies may potentiate 
clinical benefit with alternative therapies such as ASV, whereas this benefit was not realized in prior clinical trials before the debut of both ARNI and SGLT2 inhibitor therapy.

In the acute phase of decompensated heart failure, early de novo administration of beta-blocker therapy is generally contraindicated given the risk of worsening cardiac output due to negative inotropic effects in the presence of pulmonary congestion [19]. This may be a time point when ASV can be utilized to more immediately alleviate congestion and thus shorten the period to initiation of foundational medical therapy [20].

\section{Adjustment of Adaptive Servo-Ventilation Therapy}

The indications, pressure settings, and timing of termination need to be identified during ASV therapy. For successful ASV therapy and avoidance of congestion, the baseline existence of pulmonary congestion is necessary to be confirmed [13]. Inappropriate ASV therapy for those without pulmonary/systemic congestion would rather decrease cardiac output, deteriorate hemodynamics, and increase cardiovascular mortality and morbidity.

Recently, remote dielectric sensing $\left(\operatorname{ReDS}^{\mathrm{TM}}\right.$, Sensible Medical Innovations Ltd., Netanya, Israel) system, which is a noninvasive electromagnetic-based technology to quantify lung fluid volume, has been introduced in the clinical setting (Figure 2) [21]. Prior work has demonstrated the correlation between ReDS value and lung fluid level measured by high-resolution computed tomography [22,23]. The ReDS system is a promising tool to accurately assess for pulmonary congestion and may be an appropriate precursor modality to screen for patients that may benefit from early ASV therapy when decompensated heart failure is suspected.

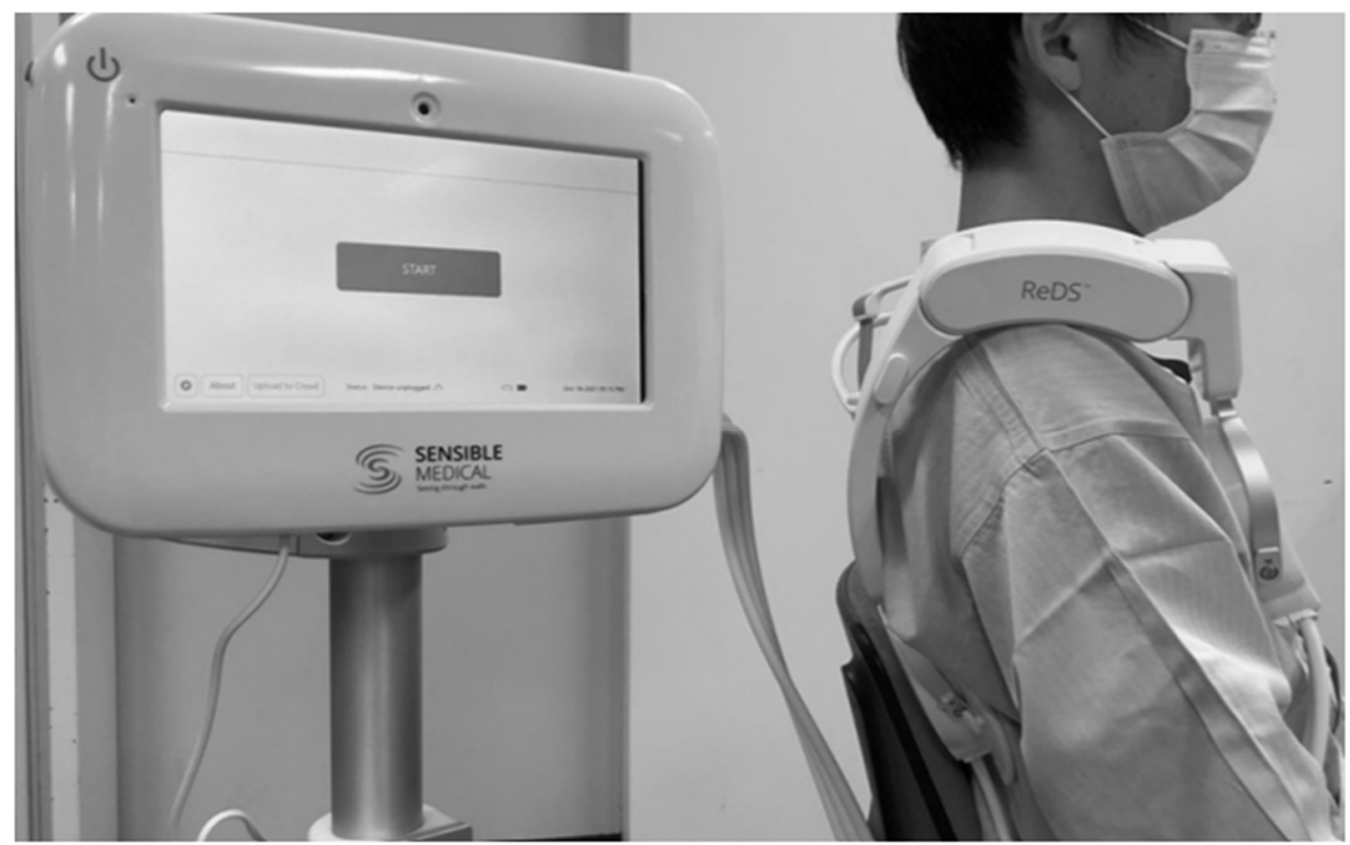

Figure 2. A monitor and a sensor of the remote dielectric sensing system.

Another novel tool in the care of heart failure patients is the AESCULON mini ${ }^{\mathrm{TM}}$ (Osypka Medical, Berlin, Germany), which noninvasively estimates cardiac output (Figure 3) [24]. With ASV therapy, inappropriately high pressure settings may rather lower cardiac output during the ASV therapy [12]. We thus propose a pressure ramp test, during which cardiac output is measured at each pressure setting to optimize end-expiratory pressure to accompany maximum cardiac output (Figure 3) [25]. ReDS values might also be measured during the pressure ramp test to assess lung fluid levels at each pressure setting [26]. 
A.

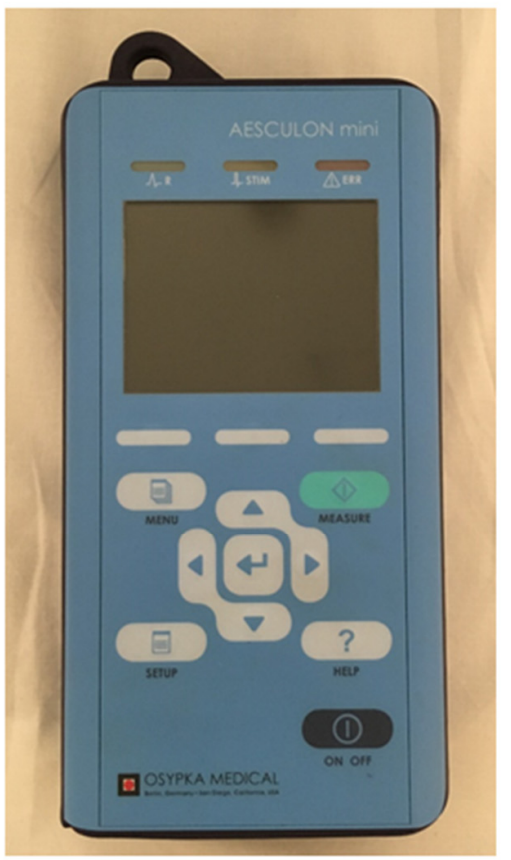

B.

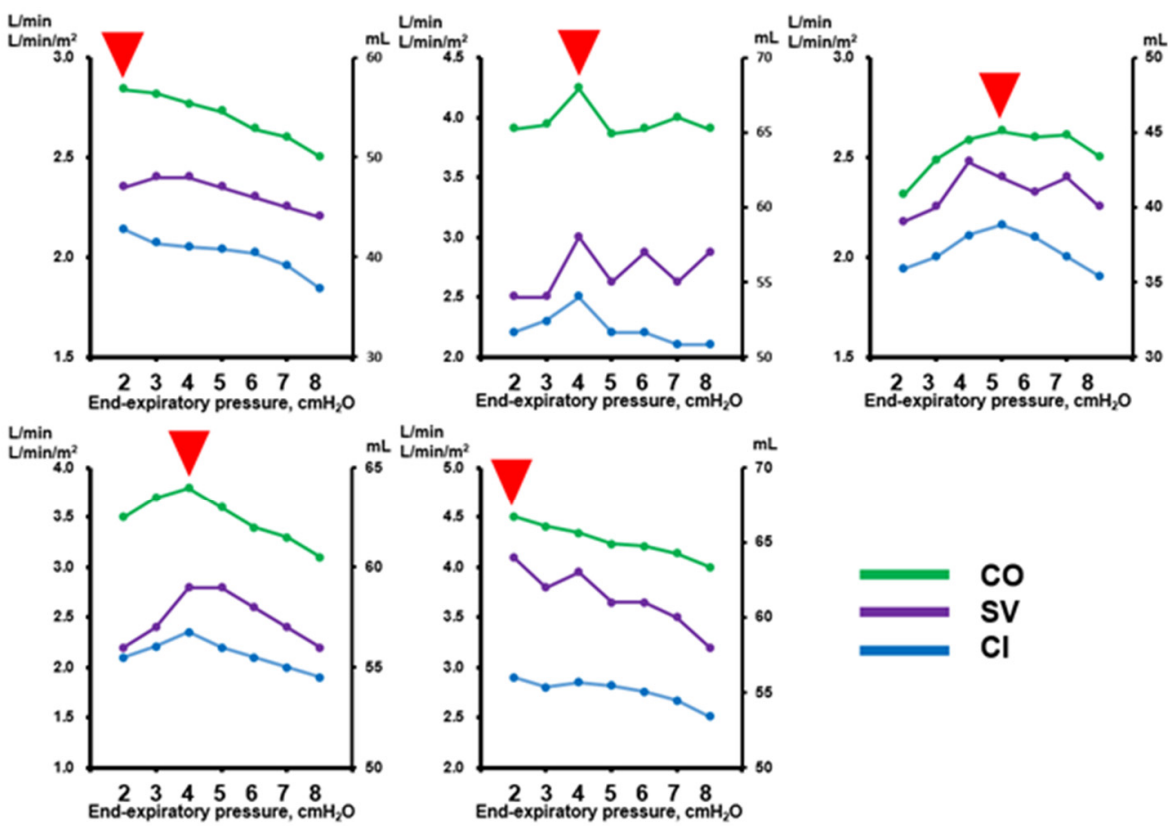

Figure 3. ASESCULON mini device (A) and examples of pressure ramp test (B) [25]. Red arrow heads indicate end-expiratory pressures with maximum cardiac output. $\mathrm{CO}$, cardiac output; SV, stroke volume; CI, cardiac index.

Continuation of ASV after improvement in clinical congestion is not encouraged and may explain the lack of superior clinical benefit in the SAVIOR-C randomized control trial [10]. However, optimal methodologies for clinicians deciding the appropriate timing to terminate ASV therapy remain unestablished. Monitoring of daily congestion through utilization of the ReDS system, in addition to congestion-related biomarkers including adrenomedullin, should allow the clinicians to accurately tailor the use of ASV. When ReDS value trends to decrease, we should consider terminating the ASV therapy to avoid hemodynamic deterioration.

\section{Renoprotection}

A cardiorenal syndrome is an additional clinical syndrome within heart failure presentations which is independently associated with worse clinical outcomes [27]. Unoptimized chronic heart failure can lead to renal congestion, decreased renal perfusion and further downstream activation of inflammatory and maladaptive neurohormonal pathways. Renal impairment worsens volume overload, subsequentially increasing cardiovascular preload and afterload.

Up-titration of loop diuretics is one option to manage volume overload triggered by progressive chronic kidney disease. However, high-dose diuretics are associated with inappropriate stimulation of the renin-angiotensin system, and may further worsen renal function [4]. Angiotensin-converting enzyme inhibitor, ARNIs, and mineralocorticoid receptor antagonist may increase serum creatinine and potassium levels particularly in elderly patients with chronic kidney disease [28,29].

ASV therapy might be a promising alternative to manage congestion while maintaining renal function. We recently demonstrated that ASV therapy maintained renal function by comparison with the pre-ASV treatment period (i.e., pretreatment versus on-treatment) [30]. Underlying mechanisms should be multifactorial. Improvement of cardiac output following the initiation of ASV supports would enhance renal perfusion and ameliorate renal ischemia. 
Suppression of sympathetic nerve activity by respiratory stabilization would dilate the renal artery and maintain renal perfusion, as well as prevent the progression of renal tissue apoptosis and fibrosis. Of note, those who achieved a reduction in diuretics dosage had greater long-term renal function preservation. Thus, ASV therapy might have a direct and indirect protective effect on kidney function.

Other therapies may also have the potential to preserve kidney function. Tolvaptan, a vasopressin type-2 receptor antagonist, may have a neutral impact on renal function as opposed to conventional loop diuretics. Tolvaptan has potent aquaretic properties and may decrease the dosage needed of typical loop diuretics, though in some countries this presents a cost challenge [8]. SGLT2 inhibitors, in addition to being associated with significant clinical benefits in patients with chronic heart failure, have also been shown to have considerable renoprotective effects in a large-scale randomized control trial [17]. One of the proposed mechanisms is the regulation of tubularglomerular feedback. Although further studies are needed, sacubitril/valsartan might also slow the worsening of renal function through an improvement in ventricular function and lowering the volume and pressure burden experienced by kidneys [31]. Although categorized as a mineralocorticoid receptor antagonist, the newly introduced esaxerenone might reduce proteinuria and better preserve renal function [32]. Another nonsteroidal, selective mineralocorticoid receptor antagonist, finerenone, may also suppress progression of chronic kidney disease and prevent cardiovascular events [33]. The combination of these heart failure therapies with ASV may be a promising strategy to manage cardiorenal syndrome.

\section{Conclusions}

In the current era with a new regimen of available medical therapies for heart failure, a combination of ASV and medical therapy may be a promising option for patients with considerable congestion and impaired renal function.

Author Contributions: Conceptualization, T.I.; methodology, T.I.; software, T.I.; validation, K.K.; formal analysis, T.I.; investigation, T.I.; resources, K.K.; data curation, T.I.; writing-original draft preparation, T.I.; writing-review and editing, N.N.; visualization, T.I.; supervision, K.K.; project administration, T.I.; funding acquisition, K.K. All authors have read and agreed to the published version of the manuscript.

Funding: This research received no external funding.

Informed Consent Statement: Informed consent was obtained from the volunteer.

Data Availability Statement: Data are available on appropriate requests.

Conflicts of Interest: The authors declare no conflict of interest.

\section{References}

1. Crespo-Leiro, M.G.; Metra, M.; Lund, L.H.; Milicic, D.; Costanzo, M.R.; Filippatos, G.; Gustafsson, F.; Tsui, S.; Barge-Caballero, E.; De Jonge, N.; et al. Advanced heart failure: A position statement of the Heart Failure Association of the European Society of Cardiology. Eur. J. Heart Fail. 2018, 20, 1505-1535. [CrossRef]

2. Vaduganathan, M.; Claggett, B.L.; Jhund, P.S.; Cunningham, J.W.; Pedro Ferreira, J.; Zannad, F.; Packer, M.; Fonarow, G.C.; McMurray, J.J.V.; Solomon, S.D. Estimating lifetime benefits of comprehensive disease-modifying pharmacological therapies in patients with heart failure with reduced ejection fraction: A comparative analysis of three randomised controlled trials. Lancet 2020, 396, 121-128. [CrossRef]

3. Tsutsui, H.; Ide, T.; Ito, H.; Kihara, Y.; Kinugawa, K.; Kinugawa, S.; Makaya, M.; Murohara, T.; Node, K.; Saito, Y.; et al. JCS/JHFS 2021 Guideline Focused Update on Diagnosis and Treatment of Acute and Chronic Heart Failure. Circ. J. Off. J. Jpn. Circ. Soc. 2021, 85, 2252-2291. [CrossRef]

4. $\quad$ Mullens, W.; Damman, K.; Harjola, V.P.; Mebazaa, A.; Brunner-La Rocca, H.P.; Martens, P.; Testani, J.M.; Tang, W.H.W.; Orso, F.; Rossignol, P.; et al. The use of diuretics in heart failure with congestion-A position statement from the Heart Failure Association of the European Society of Cardiology. Eur. J. Heart Fail. 2019, 21, 137-155. [CrossRef]

5. Rivas-Lasarte, M.; Maestro, A.; Fernandez-Martinez, J.; Lopez-Lopez, L.; Sole-Gonzalez, E.; Vives-Borras, M.; Montero, S.; Mesado, N.; Pirla, M.J.; Mirabet, S.; et al. Prevalence and prognostic impact of subclinical pulmonary congestion at discharge in patients with acute heart failure. ESC Heart Fail. 2020, 7, 2621-2628. [CrossRef] [PubMed] 
6. Jentzer, J.C.; DeWald, T.A.; Hernandez, A.F. Combination of loop diuretics with thiazide-type diuretics in heart failure. J. Am. Coll. Cardiol. 2010, 56, 1527-1534. [CrossRef] [PubMed]

7. Plosker, G.L. Tolvaptan. Drugs 2010, 70, 443-454. [CrossRef]

8. Imamura, T.; Kinugawa, K. Update of acute and long-term tolvaptan therapy. J. Cardiol. 2019, 73, 102-107. [CrossRef]

9. Momomura, S. Treatment of Cheyne-Stokes respiration-central sleep apnea in patients with heart failure. J. Cardiol. 2012, 59, 110-116. [CrossRef]

10. Momomura, S.; Seino, Y.; Kihara, Y.; Adachi, H.; Yasumura, Y.; Yokoyama, H.; Wada, H.; Ise, T.; Tanaka, K.; SAVIOR-C investigators. Adaptive servo-ventilation therapy for patients with chronic heart failure in a confirmatory, multicenter, randomized, controlled study. Circ. J. Off. J. Jpn. Circ. Soc. 2015, 79, 981-990. [CrossRef]

11. Cowie, M.R.; Woehrle, H.; Wegscheider, K.; Angermann, C.; d'Ortho, M.P.; Erdmann, E.; Levy, P.; Simonds, A.K.; Somers, V.K.; Zannad, F.; et al. Adaptive Servo-Ventilation for Central Sleep Apnea in Systolic Heart Failure. N. Engl. J. Med. 2015, 373, 1095-1105. [CrossRef] [PubMed]

12. Cowie, M.R.; Wegscheider, K.; Teschler, H. Adaptive Servo-Ventilation for Central Sleep Apnea in Heart Failure. N. Engl. J. Med. 2016, 374, 687-688. [CrossRef]

13. Imamura, T.; Kinugawa, K. What is the Optimal Strategy for Adaptive Servo-Ventilation Therapy? Int. Heart J. 2018, 59, 683-688. [CrossRef] [PubMed]

14. Boorsma, E.M.; Ter Maaten, J.M.; Damman, K.; Dinh, W.; Gustafsson, F.; Goldsmith, S.; Burkhoff, D.; Zannad, F.; Udelson, J.E.; Voors, A.A. Congestion in heart failure: A contemporary look at physiology, diagnosis and treatment. Nat. Rev. Cardiol. 2020, 17, 641-655. [CrossRef] [PubMed]

15. McMurray, J.J.; Packer, M.; Desai, A.S.; Gong, J.; Lefkowitz, M.P.; Rizkala, A.R.; Rouleau, J.L.; Shi, V.C.; Solomon, S.D.; Swedberg, K.; et al. Angiotensin-neprilysin inhibition versus enalapril in heart failure. N. Engl. J. Med. 2014, 371, 993-1004. [CrossRef]

16. Selvaraj, S.; Claggett, B.; Pozzi, A.; McMurray, J.J.V.; Jhund, P.S.; Packer, M.; Desai, A.S.; Lewis, E.F.; Vaduganathan, M.; Lefkowitz, M.P.; et al. Prognostic Implications of Congestion on Physical Examination Among Contemporary Patients With Heart Failure and Reduced Ejection Fraction: PARADIGM-HF. Circulation 2019, 140, 1369-1379. [CrossRef]

17. Heerspink, H.J.L.; Stefansson, B.V.; Correa-Rotter, R.; Chertow, G.M.; Greene, T.; Hou, F.F.; Mann, J.F.E.; McMurray, J.J.V.; Lindberg, M.; Rossing, P.; et al. Dapagliflozin in Patients with Chronic Kidney Disease. N. Engl. J. Med. 2020, 383, 1436-1446. [CrossRef]

18. Nakagaito, M.; Imamura, T.; Joho, S.; Ushijima, R.; Nakamura, M.; Kinugawa, K. Renoprotective effects of sodium glucose cotransporter 2 inhibitors in type 2 diabetes patients with decompensated heart failure. BMC Cardiovasc. Disord. 2021, 21, 347. [CrossRef]

19. Lee, H.Y.; Baek, S.H. Optimal Use of Beta-Blockers for Congestive Heart Failure. Circ. J. Off. J. Jpn. Circ. Soc. 2016, 80, 565-571. [CrossRef]

20. Nakano, S.; Kasai, T.; Tanno, J.; Sugi, K.; Sekine, Y.; Muramatsu, T.; Senbonmatsu, T.; Nishimura, S. The effect of adaptive servo-ventilation on dyspnoea, haemodynamic parameters and plasma catecholamine concentrations in acute cardiogenic pulmonary oedema. Eur. Heart J. Acute Cardiovasc. Care 2015, 4, 305-315. [CrossRef]

21. Amir, O.; Rappaport, D.; Zafrir, B.; Abraham, W.T. A novel approach to monitoring pulmonary congestion in heart failure: Initial animal and clinical experiences using remote dielectric sensing technology. Congest. Heart Fail. 2013, 19, 149-155. [CrossRef]

22. Amir, O.; Azzam, Z.S.; Gaspar, T.; Faranesh-Abboud, S.; Andria, N.; Burkhoff, D.; Abbo, A.; Abraham, W.T. Validation of remote dielectric sensing (ReDS) technology for quantification of lung fluid status: Comparison to high resolution chest computed tomography in patients with and without acute heart failure. Int. J. Cardiol. 2016, 221, 841-846. [CrossRef] [PubMed]

23. Imamura, T.; Gonoi, W.; Hori, M.; Ueno, Y.; Narang, N.; Onoda, H.; Tanaka, S.; Nakamura, M.; Kataoka, N.; Ushijima, R.; et al Validation of Noninvasive Remote Dielectric Sensing System to Quantify Lung Fluid Levels. J. Clin. Med. 2021, 11, 164. [CrossRef]

24. Nakayama, A.; Iwama, K.; Makise, N.; Domoto, Y.; Ishida, J.; Morita, H.; Komuro, I. Use of a Non-invasive Cardiac Output Measurement in a Patient with Low-output Dilated Cardiomyopathy. Intern. Med. 2020, 59, 1525-1530. [CrossRef] [PubMed]

25. Hori, M.; Imamura, T.; Narang, N.; Kinugawa, K. Pressure ramp testing for optimization of end-expiratory pressure settings in adaptive servo-ventilation therapy. Circ. Rep. 2022, 4, 17-24. [CrossRef]

26. Hori, M.; Imamura, T.; Oshima, A.; Onoda, H.; Kinugawa, K. Novel ramp test to optimize pressure setting of adaptive servoventilation using non-invasive lung fluid level quantification. Am. J. Case Rep. 2022; in press.

27. Schefold, J.C.; Filippatos, G.; Hasenfuss, G.; Anker, S.D.; von Haehling, S. Heart failure and kidney dysfunction: Epidemiology, mechanisms and management. Nat. Rev. Nephrol. 2016, 12, 610-623. [CrossRef] [PubMed]

28. Vardeny, O.; Claggett, B.; Anand, I.; Rossignol, P.; Desai, A.S.; Zannad, F.; Pitt, B.; Solomon, S.D.; Randomized Aldactone Evaluation Study (RALES) Investigators. Incidence, predictors, and outcomes related to hypo- and hyperkalemia in patients with severe heart failure treated with a mineralocorticoid receptor antagonist. Circ. Heart Fail. 2014, 7, 573-579. [CrossRef]

29. Rossignol, P.; Dobre, D.; McMurray, J.J.; Swedberg, K.; Krum, H.; van Veldhuisen, D.J.; Shi, H.; Messig, M.; Vincent, J.; Girerd, N.; et al. Incidence, determinants, and prognostic significance of hyperkalemia and worsening renal function in patients with heart failure receiving the mineralocorticoid receptor antagonist eplerenone or placebo in addition to optimal medical therapy: Results from the Eplerenone in Mild Patients Hospitalization and Survival Study in Heart Failure (EMPHASIS-HF). Circ. Heart Fail. 2014, 7, 51-58. [CrossRef] [PubMed]

30. Imamura, T.; Hori, M.; Narang, N.; Kinugawa, K. Association Between Adaptive Servo-Ventilation Therapy and Renal Function. Int. Heart J. 2021, 62, 1052-1056. [CrossRef] 
31. Spannella, F.; Giulietti, F.; Filipponi, A.; Sarzani, R. Effect of sacubitril/valsartan on renal function: A systematic review and meta-analysis of randomized controlled trials. ESC Heart Fail. 2020, 7, 3487-3496. [CrossRef] [PubMed]

32. Oshima, A.; Imamura, T.; Narang, N.; Kinugawa, K. Renoprotective Effect of the Mineralocorticoid Receptor Antagonist Esaxerenone. Circ. Rep. 2021, 3, 333-337. [CrossRef] [PubMed]

33. Bakris, G.L.; Agarwal, R.; Anker, S.D.; Pitt, B.; Ruilope, L.M.; Rossing, P.; Kolkhof, P.; Nowack, C.; Schloemer, P.; Joseph, A.; et al. Effect of Finerenone on Chronic Kidney Disease Outcomes in Type 2 Diabetes. N. Engl. J. Med. 2020, 383, 2219-2229. [CrossRef] [PubMed] 